\title{
A Few Lessons from my Long Experience in IB Research - Opinion/Editorial:
}

\author{
Yair Aharoni, Tel Aviv University, Israel
}

My LONG EXPERIENCE IN IB RESEARCH has taught me several lessons which may resemble or differ from the experiences of other researchers. I offer some of them in order to elicit your comments and generate a discussion among us. This paper is not a summary of my research work. Rather, I wanted to reflect on what I consider a few of the major challenges and implications for IB researchers.

Let me start by arguing the importance of talking to practitioners in order to get a real grasp of a problem or practice - often resulting in case studies rather than analyses of secondary data or questionnaire surveys. In 1959-1961, when I was doing my doctoral research at Harvard Business School, I was distressed by the apparent failure of Israel to attract foreign direct investments, despite the fervent attempts by the government to encourage it by enacting the Law for the Encouragement of Capital Investments. From my training in economics, I assumed that the conferral of tax benefits would induce foreign investors to initiate projects which they would not otherwise have undertaken. The problem seemed to be straightforward - how large did the tax incentives need to be?

I could have designed a questionnaire asking a carefully chosen sample of managers to rank the size of the tax holiday they would require in order to make a foreign investment, and added some other questions on related topics. I am sure that I would have received answers that could have been tabulated and regressed against other variables, and I am equally certain that the answers would have indicated that tax holidays are desirable - after all, what managers would answer that they would not want these tax holidays?

However, Harvard Business School required case writing as an integral part of doctoral research. I made a list of firms that had considered an investment in Israel and wrote about 40 case studies on the history of the decisions, based on interviewing managers and reading correspondence and other documents related to the decision. I soon found out that tax incentives did not play the decisive role I had expected them to play. Moreover, the picture emerging from my field research seemed to be one of utterly irrational behavior. The "decision process" followed by US businesspeople had very little in common with the classical economic theory of capital investment. To understand their behavior, it was necessary to recognize that decisions are made under uncertainty within an organizational and social system. Once I changed my research lens, what seemed irrational made sense. I could offer a behavioral theory that explained how and why decisions are made and how and why commitments accumulate. In 1966, I published a book based on my findings which are well known so I will not repeat them (Aharoni, 1966).

Had I chosen to study foreign investments through a mail questionnaire, however carefully designed, I would never have been exposed to the rich saga of the real foreign investment decision process and to the way real managers in real firms make decisions. Rather I could have suggested wrong policies. Since then, I have written more than 150 cases on all kinds of problems and researched a variety of issues. In this work, I have consistently benefited from the insights of businessmen. To be sure, I did not always rely on case studies and interviews since, in some of my studies, I used carefully designed questionnaires. Yet I have always tried to understand the actual behavior of persons within a firm - not how they should behave.

A second key point is that I expect IB scholars to study management rather than economics. IB scholars try to be as scientific as those in the natural sciences. Many of these researchers (including myself) were trained as economists, and economists prefer to apply econometric methods to what is perceived as descriptive research. The quest for additional rigor calls for a solid analysis of a large number of observations. Unfortunately, to achieve rigor, the researchers find themselves very distant from reality, which is socially and politically constructed rather than objectively determined. The pioneers of scientific management attempted to discover general rules of behavior such as the number of hierarchical levels or the span of control which were assumed to be pertinent to all organizations. Only decades later were contingent variables introduced. IB researchers also preferred to look for general rules and ignored contingent variables. Yet human behavior is very complex, and executives are also family members, belong to different clubs and interest groups and are citizens of a nation - and all of these affiliations impact on their behavior. Moreover, as Simon (1955) pointed out in the 1950s, they do not maximize. Since then, generations of behavioral economists - but unfortunately not IB scholars - have followed in his footsteps.

Classical economics-based theory alone is insufficient to understand the complexity of real life. We must incorporate politics, culture and 
institutions. Only if all of these approaches are woven into our theories may they be helpful for businessmen and for policy makers. One example is what I term "political strategy" - that is, concentrating on getting benefits from the government rather than on achieving competitive advantages in the marketplace. In a democratic society, power is diffused throughout the society, the spectrum of interest groups is wide and business itself is one of the most powerful organized interest groups. Some firms are state-owned and all large firms spend resources on lobbying. They have great political power - particularly, in small countries - but they are also deeply affected by the government and other environmental forces. Thus, when the government abandons its import-substitution policies and exposes firms to foreign competition, many firms go bankrupt.

In 1970, I taught at IMEDE, where I embarked on an intensive case-research effort on business-government interactions (Aharoni \& Baden, 1977). I was able to identify the relevant actors in each situation and assess their strengths both in their home as well as in their host countries. I also found that human material needs are being satisfied to a larger extent through political mechanisms rather than through the market. I also studied boards of directors and the differences among state, trade-union and privately owned enterprises in Israel. I found that professional managers have the same objectives, aspirations and belief systems, irrespective of their firms' owners - be they the state, trade unions or private-sector owners. They pursue what they see as the firm's best interests, disregarding instructions. The simplistic views on the efficacy of planning or that of the market mechanism are both wrong. In my view, the key issue is to design objective and transparent systems for electing the best managers and directors and to avoid political appointments. These managers act within an uncertain environment of norms and institutions and, again, economic-based theory is not sufficient to understand the complexity of real life. The examples above illustrate that we must consider political, cultural and social factors, and acknowledge uncertainty.

Third, IB research is very much context-specific. It does not necessarily apply to different environments and diverse contexts nor is it independent of these factors. Researchers may study a large population and reach wrong conclusions because the choice of the population studied was not a representative sample. Thus, many observations on the behavior of manufacturing firms do not hold for services. As one example, many IB scholars have assumed that firms seek to control their subsidiaries to protect their intellectual property and therefore insist on full ownership. Yet hotel chain management seems to prefer joint ventures and use this form even when the government allows full ownership (more examples may be found in Aharoni (1997)). By the same token, many of the conclusions reached by Porter (1990) are the result of studying mainly US-based large corporations. However, many Israeli, Canadian and Danish firms did not grow first in their home market. In fact, the Israeli high-technology industry exports more than 90 percent of its output, and in several cases, the firm does not sell in Israel at all! Clearly, a tiny country with a very limited market size faces different issues than a large country. Theories based on the experience of US firms may not be applicable to small countries.

My case research showed that successful firms did not attempt to compete head on against foreign giants. Instead, they identified a particular market niche in which they basically had a monopoly — being the only firm that supplied a certain unique product or service. This observation was even more relevant in international operations. Israeli firms cannot even hope to compete head on in the global market against the giant multinational firms. They can, however, be very successful when they define a niche that is either ignored (often because of its size) or unknown to the giant firms in the industry.

Strategy, I suggest as my fourth point, is not about gaining competitive advantage in an industry but about creating a monopoly in a well-defined niche. In other words, strategy is about being an outlier and being unique - not about being part of the herd. A large flow of statistically based research efforts attempt to connect industry structure with strategy, performance or other variables. Yet a successful competitor creates an industry, achieving success by being unique in a certain specific and well-identified niche within which this firm does not compete but which it dominates.

Having studied managerial behavior and its interaction with government in a small and relatively less-developed country, I was curious to find out whether things were different in the United States and other developed countries. The result was a book I called The No-Risk Society (1981), which showed that demands for social justice and equity have turned into calls for more publicly provided insurance and fewer private risks. Governments are expected to reduce or shift the risks once borne by individuals, immunize the latter against almost any change and insure them against any conceivable hazard. Ironically, government programs to reduce risks have the effect of encouraging people to be more reckless in a new version of moral hazard - a "culture of dependency," the erosion of individual responsibility, the decline of the entrepreneurial spirit and a "no-risk society" in the end. Both successful entrepreneurs and long-established businesses do take risks, but they do so against a background of extensive protections and hedges, many of them - such as the $\$ 500$ billion savings and loans bailout in the US - being supplied at the taxpayers' expense. The expense of these programs is not confined to the public budget. Individuals demand less government yet clamor for public benefits so that the public also pays invisible taxes in the form of regulations that protect business from competition. If a firm begins to falter, the government may rescue it through loans, subsidies or protective trade agreements. The new version of moral hazard became apparent when, in the financial crisis of 2008, it was taken for granted that firms may be "too big to fail," thereby reinforcing the importance of political factors.

Finally, the MNEs of several dozens of years ago extracted rents from existing resources and knowledge developed at home. In an ever-shifting turbulent environment, they are learning to adapt themselves to the changing environment and to develop new capabilities through a globally coordinated network. In this network, knowledge can be developed in any subsidiary and then transferred to the whole network. 
I have offered my ideas on a few of the issues I observed in my IB research and I am interested to read about your experiences in this area.

\section{References}

Aharoni, Y. 1966. The foreign investment decision process. Boston, MA: Harvard Business School Press.

Aharoni, Y. 1981. The no-risk society. Chatham, NJ: Chatham House

Aharoni, Y. 1993. The internationalization process in professional business service firms: Some tentative conclusions. In Y. Aharoni (Ed.), Coalitions and competition: The globalization of professional business services: 280-285. Florence, KY: Routledge.

Aharoni, Y. (Ed.). 1997. Changing roles of state intervention in services in an era of open international markets. Albany, NY: SUNY Press.

Aharoni, Y., \& Baden, C. 1977. Business in the international environment. London: Macmillan.

Aharoni, Y., \& Lachman, R. 1982. Can the manager's mind be nationalized? Organization Studies, 3(1): 33-46

Porter, M. E. 1990. The competitive advantage of nations. New York: Free Press.

Simon, H. 1955. A behavioral model of rational choice. Quarterly Journal of Economics, 69: 99-188.
Yair Aharoni is Professor Emeritus at the faculty of management, Tel-Aviv University, a Fellow of the International Academy of Management and the Academy of International Business. During his long and distinguished academic career, Aharoni was the Daniel and Grace Ross professor of International Business and later the Issachar Haimovic Professor of Business Policy — both at Tel Aviv University. He was the Thomas Henry Caroll Ford Foundation Visiting Professor of Business Administration, Harvard Graduate School of Business Administration. (197879). He was also the J.Paul Stitch Visiting Professor of International Business at Duke University (1987-1995) and the director of CIBER (Center of International Business Education and Research). (1992-1995). He published several dozen books and monographs in Hebrew and in English , more than hundred papers and chapters in books and more than 150 cases. For his academic achievements he was awarded both Landau Prize (2007) and Israel Prize in management science.(2010). 